\title{
Nanosheet formation by an anionic surfactant-like peptide and modulation of self-assembly through ionic complexation
}

Article

Published Version

Creative Commons: Attribution 4.0 (CC-BY)

Open Access

Hamley, I. W., Hutchinson, J., Kirkham, S., Castelletto, V., Kaur, A., Reza, M. and Ruokolainen, J. (2016) Nanosheet formation by an anionic surfactant-like peptide and modulation of self-assembly through ionic complexation. Langmuir, 32 (40). pp. 10387-10393. ISSN 0743-7463 doi:

https://doi.org/10.1021/acs.langmuir.6b02180 Available at https://centaur.reading.ac.uk/68326/

It is advisable to refer to the publisher's version if you intend to cite from the work. See Guidance on citing.

Published version at: http://dx.doi.org/10.1021/acs.langmuir.6b02180

To link to this article DOI: http://dx.doi.org/10.1021/acs.langmuir.6b02180

Publisher: American Chemical Society

All outputs in CentAUR are protected by Intellectual Property Rights law, including copyright law. Copyright and IPR is retained by the creators or other copyright holders. Terms and conditions for use of this material are defined in the End User Agreement. 


\section{CentAUR}

Central Archive at the University of Reading

Reading's research outputs online 


\title{
Nanosheet Formation by an Anionic Surfactant-like Peptide and Modulation of Self-Assembly through lonic Complexation
}

\author{
Ian W. Hamley,* Jessica Hutchinson, Steven Kirkham, Valeria Castelletto, and Amanpreet Kaur \\ Department of Chemistry, University of Reading, Whiteknights, Reading RG6 6AD, U.K.
}

Mehedi Reza and Janne Ruokolainen

Department of Applied Physics, Aalto University School of Science, P. O. Box 15100, FI-00076 Aalto, Finland

\section{Supporting Information}

\begin{abstract}
The surfactant-like peptide $(\mathrm{Ala})_{6^{-}}(\mathrm{Asp})\left(\mathrm{A}_{6} \mathrm{D}\right)$ is shown to self-assemble into ultrathin ( $3 \mathrm{~nm}$ thick) nanosheets in aqueous solution above a critical aggregation concentration. A combination of circular dichroism and FTIR spectroscopy and X-ray diffraction shows that the nanosheets comprise interdigitated bilayers of the peptide with $\beta$-sheet conformation. The self-assembly can be modulated by addition of hexamethylenediamine which is expected to interact with the anionic $C$ terminus (and C-terminal D residue) of the peptide. Multiple ordered nanostructures can be accessed depending on the amount of added diamine. Nanosheet and bicontinuous network structures were observed using cryogenic-TEM and small-angle X-ray scattering. Addition of hexamethylenediamine at a sufficiently large molar ratio leads to disruption of the ordered nanostructure and the formation of a solution of $\mathrm{A}_{6} \mathrm{D}$-diamine molecular complexes with highly charged end groups. The multiple acid-functionalized nanostructures that are accessible in this system are expected to have many applications in the fabrication of new nanomaterials.
\end{abstract}

\section{INTRODUCTION}

The formation of free-floating ultrathin nanosheet structures has been observed for several classes of systems including assemblies with graphene or graphene oxide, ${ }^{1,2}$ two-dimensional metal oxide sheets, ${ }^{3,4}$ various exfoliated inorganic structures, ${ }^{5}$ polymer ${ }^{6}$ and block copolymer crystals, ${ }^{7}$ and peptoids. $^{8-10}$ Nanosheet formation by peptides is rarely reported, ${ }^{1-16}$ although such structures offer the potential to prepare functional nanostructures coated at high density with bioactive amino acids.

Surfactant-like peptides (SLPs) have a remarkable ability to self-assemble into different nanostructures, primarily due to their amphiphilic nature. For example, they can aggregate into high aspect ratio structures while displaying bioactive peptides. SLPs are a class of amphiphilic peptide comprising a headgroup which is a short sequence of charged residues attached to a tailgroup of neutral residues. ${ }^{17-19}$ Pioneering work on SLPs has been conducted by the Zhang group including a series of peptides with neutral amino acid tails (based on valine, alanine, or glycine) and charged residues such as D (aspartic acid) or $\mathrm{K}$ (lysine).$^{20-23}$ We previously reported the unexpected observation that the SLP $\mathrm{A}_{6} \mathrm{R}$ self-assembles into free-floating ultrathin ( $3 \mathrm{~nm}$ thick) nanosheets in dilute aqueous solution. ${ }^{12}$ At higher concentration, the nanosheets wrap into helical ribbons and nanotubes. Here we report on the self-assembly of the related SLP $A_{6} D$ with oppositely charged headgroup compared to $A_{6} R$, and we show that the self-assembly can be modulated by addition of diamine, expected to bind to the peptide $\mathrm{C}$ terminus and the carboxyl group in the $\mathrm{D}$ residue.

The self-assembly of $\mathrm{Ac}-\mathrm{A}_{6} \mathrm{D}-\mathrm{OH}$ (N-terminal capped; charge of -2 at $\mathrm{pH} 7$ ) has been studied in phosphate-buffered solution (PBS) ${ }^{24}$ or in water. ${ }^{21}$ In PBS, light scattering revealed a critical aggregation concentration (CAC), and above the $\mathrm{CAC}$, atomic force microscopy revealed extended structures interpreted as nanotubes, or nanotubes with bulges (which alternatively appear to be like bead aggregate structures). ${ }^{24}$ The results were compared to those for peptide $\mathrm{Ac}-\mathrm{A}_{6} \mathrm{~K}-\mathrm{CONH}_{2}$ which it is also claimed self-assembles into nanotubes. ${ }^{24}$ The influence on the CAC and on the self-assembled nanostructure was investigated for mixtures of $\mathrm{Ac}-\mathrm{A}_{6} \mathrm{D}-\mathrm{OH}$ and $\mathrm{Ac}-\mathrm{A}_{6} \mathrm{~K}-$ $\mathrm{NH}_{2}{ }^{25}$ "Nanorope" structures were observed for the $\mathrm{Ac}-\mathrm{A}_{6} \mathrm{D}-$ $\mathrm{OH} / \mathrm{Ac}-\mathrm{A}_{6} \mathrm{~K}-\mathrm{NH}_{2}=2: 1$ molar ratio mixture. ${ }^{25}$ A study using circular dichroism to determine secondary structure found that $\mathrm{Ac}-\mathrm{A}_{6} \mathrm{D}-\mathrm{OH}$ adopts a mostly random coil structure in dilute aqueous solution, with some $\beta$-sheet content at higher concentration. ${ }^{26}$ Peptides including $\mathrm{Ac}-\mathrm{A}_{6} \mathrm{D}-\mathrm{OH}$ have been used as surfactants in commercial Escherichia coli (E. coli) cellfree systems to produce soluble G-protein coupled receptors. ${ }^{27}$ Another potential application involves nanovesicles for drug delivery since $\mathrm{Ac}-\mathrm{A}_{6} \mathrm{D}-\mathrm{OH}$ has been reported to form

Received: June 13, 2016

Revised: August 30, 2016

Published: September 16, 2016 
nanovesicles and nanovesicle clusters under defined phosphate buffered saline conditions (in contrast to the above-mentioned works). ${ }^{28}$ This peptide has also been used along with a zwitterionic surfactant to template the formation and deposition (at nanotube or nanobelt walls) of gold nanoparticles. $^{29}$ The influence of SLPs such as $\mathrm{A}_{6} \mathrm{D}$ on the structure of ternary mixtures with the lipid mono-olein and water has been examined, and it was shown to be possible to tune the size of the bicontinuous cubic phase lattice or to induce the formation of an inverse hexagonal structure. ${ }^{30}$

Here we report on the self-assembly, and secondary structure, of $\mathrm{NH}_{2}-\mathrm{A}_{6} \mathrm{D}-\mathrm{COOH}$. We note that this differs from the peptide studied by Zhang et al. as it is uncapped at both termini. We also investigate self-assembly in mixtures of $\mathrm{NH}_{2}-\mathrm{A}_{6} \mathrm{D}-\mathrm{COOH}$ with hexamethylenediamine (HEMED, 1,6-hexanediamine) and the effect of this diamine on peptide conformation. The diamine is expected to form complexes with $\mathrm{A}_{6} \mathrm{D}$ which will have a charge of +1 at $\mathrm{pH} 7$ as it contains an ionizable $-\mathrm{NH}_{2}$ group at the $\mathrm{N}$ terminus, an aspartic acid residue, and a carboxyl group at the $\mathrm{C}$ terminus. Diamines such as tetramethylenediamine (putrescine) or pentamethylenediamine (cadaverine) are important biogenic amines with a variety of functions. Here, we chose to study the complexation of $\mathrm{A}_{6} \mathrm{D}$ with hexamethylenediamine from the same series of short flexible amines.

The complexation of various amines including ethylene-, tetramethylene-, and pentamethylene diamine and spermine and spermidine with the anionic surfactant SDS has been investigated, and it has been shown that enhanced adsorption at the air-water interface results. ${ }^{31,32}$ However, to the best of our knowledge, complexation of surfactant-like peptides with diamines has not previously been examined. We show that addition of hexamethylenediamine significantly modifies the self-assembled nanostructure and that it is possible to produce nanotape and platelet structures in this way. As far as we are aware, platelet peptide nanostructures have not previously been noted.

\section{EXPERIMENTAL SECTION}

Materials. Peptide $\mathrm{NH}_{2}-\mathrm{AAAAAAD}-\mathrm{COOH}$, referred to as $\mathrm{A}_{6} \mathrm{D}$, was custom synthesized by CS Bio Co. (Menlo Park, CA, USA) and was received as the TFA salt variant. Purity was $99.87 \%$ by HPLC in water/acetonitrile (0.1\% TFA). Electrospray-ionization mass spectroscopy (ESI-MS) indicated a molar mass of $559.33 \mathrm{~g} \mathrm{~mol}^{-1}$ (559.59 g mol $^{-1}$, expected).

Pyrene Fluorescence. Fluorescence spectra were recorded with a Varian Cary Eclipse fluorescence spectrometer with samples in $4 \mathrm{~mm}$ inner quartz cuvettes. The assays were performed using $1.3 \times 10^{-3}$ to 0.13 wt $\% \mathrm{~A}_{6} \mathrm{D}$, in $2.3 \times 10^{-5}$ wt $\%$ pyrene solution, and the same $\mathrm{A}_{6} \mathrm{D}$ concentration range with $2: 1,1: 1$, and $1: 2$ molar ratios to hexamethylenediamine and $1.3 \times 10^{-4}$ wt $\%$ pyrene solution. The samples were excited at $\lambda_{\text {ex }}=339 \mathrm{~nm}$, and the fluorescence emission was measured for $\lambda=360-500 \mathrm{~nm}$.

Titration pH Measurements. A vial was filled with $1 \mathrm{wt} \%(17.88$ $\mathrm{mM}) \mathrm{A}_{6} \mathrm{D}$ to which aliquots of a $71.52 \mathrm{mM}$ diamine solution were added. $\mathrm{pH}$ was measured using a Mettler Toledo Five Easy FE20 instrument with a Sigma-Aldrich micro $\mathrm{pH}$ combination electrode, at various points as more hexamethylenediamine solution was added, until a ratio of $1: 2$ peptide:diamine was reached.

Circular Dichroism Spectroscopy. Circular dichroism (CD) spectra were recorded using a Chirascan spectropolarimeter (Applied Photophysics, Leatherhead, U.K.). The samples, with $\mathrm{A}_{6} \mathrm{D}$ always at $1 \%$, were placed in a coverslip cuvette $(0.2 \mathrm{~mm}$ thick), spectra presented being with absorbance $A<2$ at any measured point with a $0.5 \mathrm{~nm}$ step, $1 \mathrm{~nm}$ bandwidth, and $1 \mathrm{~s}$ collection time per step. The
CD signal from the background was subtracted from the $\mathrm{CD}$ data of the sample solutions.

Fourier Transform Infrared Spectroscopy. Spectra were recorded using a Thermo Scientific Nicolet IS5 or a Nexus-FTIR spectrometer, both equipped with a DTGS detector. In the former, a PEARL liquid cell was used (sample contained between fixed $\mathrm{CaF}_{2}$ plates). In the Nexus spectrometer, $20 \mu \mathrm{L}$ of each sample was sandwiched between two $\mathrm{CaF}_{2}$ plate windows (spacer, $0.012 \mathrm{~mm}$ thick). Spectra were scanned 128 times over the range of 900-4000 $\mathrm{cm}^{-1}$.

Cryogenic Transmission Electron Microscopy. Imaging was carried out using a field emission cryo-electron microscope (JEOL JEM-3200FSC), operating at $200 \mathrm{kV}$. Images were taken in bright field mode and using zero loss energy filtering ( $\Omega$ type) with a slit width of $20 \mathrm{eV}$. Micrographs were recorded using a Gatan Ultrascan $4000 \mathrm{CCD}$ camera. The specimen temperature was maintained at $-187^{\circ} \mathrm{C}$ during the imaging. Vitrified specimens were prepared using an automated FEI Vitrobot device using Quantifoil 3.5/1 holey carbon copper grids with a hole size of $3.5 \mu \mathrm{m}$. Just prior to use, grids were plasma cleaned using a Gatan Solarus 9500 plasma cleaner and then transferred into an environmental chamber of a FEI Vitrobot at room temperature and $100 \%$ humidity. Thereafter $3 \mathrm{~mL}$ of sample solution was applied onto the grid, and it was blotted twice for $5 \mathrm{~s}$ and then vitrified in a $1 / 1$ mixture of liquid ethane and propane at a temperature of $-180{ }^{\circ} \mathrm{C}$. The grids with vitrified sample solution were maintained at liquid nitrogen temperature and then cryotransferred to the microscope.

X-ray Diffraction. Measurements were performed on stalks prepared by drying filaments of solutions $A_{6} D$. The stalk for $A_{6} D$ was prepared from a $1 \mathrm{wt} \%$ solution, but for the solutions containing mixtures of $\mathrm{A}_{6} \mathrm{D}$ with diamine, $5 \mathrm{wt} \%$ solutions were used. Solutions of the mixtures were suspended between the ends of wax-coated capillaries and dried. The stalks were mounted (vertically) onto the four axis goniometer of an Oxford Diffraction Gemini Ultra instrument. The sample-detector distance was $44 \mathrm{~mm}$. The X-ray wavelength was $\lambda=1.54 \AA$. The wavenumber scale $(q=4 \pi \sin \theta / \lambda$ where $2 \theta$ is the scattering angle) was geometrically calculated. The detector was a Sapphire CCD.

Small-Angle X-ray Scattering. Collection of solution small-angle $\mathrm{X}$-ray scattering (SAXS) data was performed on the bioSAXS beamline BM29 at the ESRF, Grenoble, France. Solutions containing 1 wt \% $\mathrm{A}_{6} \mathrm{D}$ or $1 \mathrm{wt} \% \mathrm{~A}_{6} \mathrm{D}$ mixed with hexamethylenediamine were loaded in PCR tubes in an automated sample changer. SAXS data were collected using a Pilatus $1 \mathrm{M}$ detector. The sample-detector distance was 2.84 $\mathrm{m}$. The X-ray wavelength was $0.99 \AA$. The wavenumber $q=4 \pi \sin \theta / \lambda$ scale was calibrated using silver behenate.

Zeta Potential Measurements. The $\zeta$ potential was measured using a Zetasizer Nano 2s from Malvern Instruments. A $1 \mathrm{~mL}$ aliquot of sample was placed inside a disposable folded capillary cell. The sample was left to equilibrate for $120 \mathrm{~s}$ before measuring the $\zeta$ potential, using an applied voltage of $50.0 \mathrm{~V}$. The results presented are the average over three measurements.

\section{RESULTS}

We first determined whether the addition of hexamethylenediamine has any influence on the potential aggregation behavior of $\mathrm{A}_{6} \mathrm{D}$ via critical aggregation concentration (CAC) assays. Pyrene is a dye whose fluorescence is sensitive to local hydrophobic environment, widely used for such assays as in our previous work for example on $\mathrm{A}_{6}$ RGD. ${ }^{33}$ Figure 1 shows results from pyrene fluorescence $\mathrm{CAC}$ assays. A discontinuous increase in intensity occurs at the CAC. $\mathrm{A}_{6} \mathrm{D}$ itself shows a $\mathrm{CAC}=0.030$ $\pm 0.005 \mathrm{wt} \%$ with a similar value for $2: 1 \mathrm{~A}_{6} \mathrm{D}$ :diamine (in this and the following where concentration ratios are given, they refer to molar concentrations). The value for $1: 1 \mathrm{~A}_{6} \mathrm{D}$ :diamine mixtures is lower, $\mathrm{CAC}=0.0063 \pm 0.003$ wt $\%$. This presumably reflects the enhanced hydrophobicity resulting from the screening of the charge on the carboxyl group on the $\mathrm{D}$ residue and at the $\mathrm{C}$ terminus under these conditions. Most 


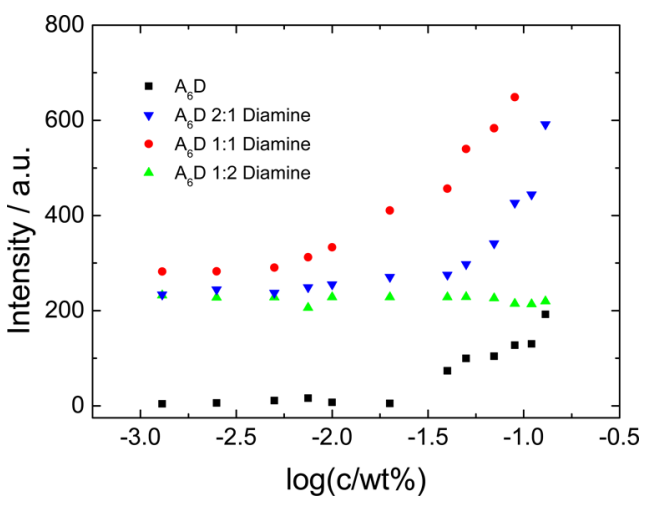

Figure 1. Critical aggregation concentration (CAC) assay using concentration-dependent pyrene (first vibronic band) fluorescence, $I_{1}$.

remarkably, however, the $\mathrm{CAC}$ for the 1:2 $\mathrm{A}_{6} \mathrm{D}$ :diamine system appears to be entirely suppressed.

This influence of molecular conformation on this unexpected phenomenon was examined using circular dichroism (CD) spectroscopy. The measured spectra are shown in Figure 2a.
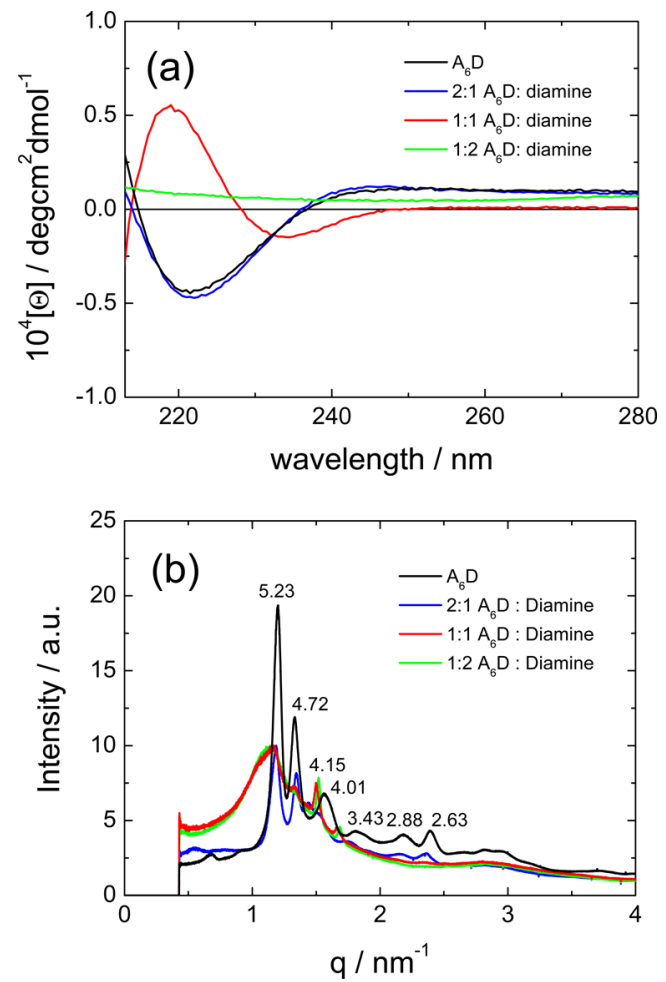

Figure 2. (a) $C D$ spectra for mixtures of $A_{6} D$ with hexamethylenediamine for the solutions indicated (constant $\mathrm{A}_{6} \mathrm{D}$ concentration, $1 \mathrm{wt}$ $\%$; ratios of $\mathrm{A}_{6} \mathrm{D}$ :diamine are molar ratios). (b) X-ray diffraction intensity profiles for $\mathrm{A}_{6} \mathrm{D}$ with hexamethylenediamine under the conditions indicated. For the $\mathrm{A}_{6} \mathrm{D}$ profile, $d$-spacings $(\AA)$ are indicated as well as the $4.15 \AA$ spacing for two of the other samples. Stalks were prepared from solutions with a constant $\mathrm{A}_{6} \mathrm{D}$ concentration, 1 wt \%.

The spectra for $\mathrm{A}_{6} \mathrm{D}$ and 2:1 $\mathrm{A}_{6} \mathrm{D}$ :diamine exhibit minima near $220 \mathrm{~nm}$ and can be assigned to peptide $\beta$-sheet conformation. $^{34,35}$ In contrast, the spectrum for a $1: 1 \quad \mathrm{~A}_{6} \mathrm{D}$ :diamine mixture is distinct with a maximum at $219 \mathrm{~nm}$ and a minimum at $234 \mathrm{~nm}$ and is ascribed to disordered conformation and/or a contribution from a turn structure. ${ }^{36}$ Remarkably, CD reveals the absence of secondary structure for the 1:2 $\mathrm{A}_{6} \mathrm{D}$ :diamine mixture. This correlates with the results from the pyrene fluorescence CAC assay for this sample which shows no break point and thus no evidence for aggregation. These findings are supported by FTIR (Supporting Information (SI) Figure S1) which show a clear amide $\mathrm{I}^{\prime}$ peak assignable to $\beta$-sheet structure $^{37-39}$ at $1625 \mathrm{~cm}^{-1}$ for $\mathrm{A}_{6} \mathrm{D}$ and the $2: 1$ mixture. However, this peak is replaced by a broad peak at $1644 \mathrm{~cm}^{-1}$ for the $1: 1$ and 1:2 mixtures, which is due to unordered conformation. Also evident is a small peak at $1700 \mathrm{~cm}^{-1}$ for the $\mathrm{A}_{6} \mathrm{D}$ and 2:1 mixture, which is absent for the other two mixtures. This peak is assigned to $\mathrm{C}=\mathrm{O}$ stretch vibrations, ${ }^{37,40}$ and its absence for the 1:1 and 1:2 mixtures is likely due to binding of the diamine. All spectra also have a peak at 1672 $\mathrm{cm}^{-1}$ due to TFA counterions bound to the $\mathrm{N}$ terminus of the peptide. ${ }^{41}$ There are also shifts in the intensity of the amide $\mathrm{II}^{\prime}$ peak at $1550 \mathrm{~cm}^{-1}$ due to $\mathrm{N}-\mathrm{H} / \mathrm{C}-\mathrm{N}$ deformations upon variation of diamine concentration. ${ }^{37}$ The FTIR spectra in the 3000-3800 $\mathrm{cm}^{-1}$ range also show a dramatic transition comparing the spectra for $\mathrm{A}_{6} \mathrm{D}$ and the 2:1 mixture with those for the 1:1 and 1:2 mixtures-the spectra in each pair showing features similar to each other. In particular, the sharp peak near $3290 \mathrm{~cm}^{-1}$ for $\mathrm{A}_{6} \mathrm{D}$ and the high $\mathrm{A}_{6} \mathrm{D}$ content mixture can be ascribed to $\mathrm{N}-\mathrm{H}$ stretching vibrations within peptide chains (non-H-bonded), whereas this peak is absent from the spectra for the $1: 1$ and 1:2 mixtures which contain a broad peak near $3400 \mathrm{~cm}^{-1}$ which is due to $\mathrm{H}$-bonded $\mathrm{N}-\mathrm{H}$ or $\mathrm{O}-\mathrm{H}$ stretch modes. ${ }^{37,40}$

Confirmation of $\beta$-sheet structure is provided by fiber X-ray diffraction (XRD). The isotropic scattering patterns were reduced to one-dimensional intensity profiles as shown in Figure $2 \mathrm{~b}$. $\mathrm{A}_{6} \mathrm{D}$ exhibits a series of reflections from an alaninerich $\beta$-sheet structure which have unusually small $\beta$-sheet spacings $^{12,42-45}$ (here $5.23 \AA$ ) along with the $4.72 \AA \beta$-strand spacing, and other peaks from the well ordered packing of the alanine residues. The 2:1 mixture sample shows the same features. In complete contrast, for the 1:1 and 1:2 $\mathrm{A}_{6} \mathrm{D}$ :diamine samples these $\beta$-sheet features are absent and instead there is a broad halo in the XRD intensity profile corresponding to a $d$ spacing around $5.5 \AA$ along with a peak corresponding to 4.15 $\AA$. These features can be assigned to unordered peptide.

The distinct aggregation behavior in the mixtures with different diamine content was examined by cryogenic transmission electron microscopy (cryo-TEM; Figure 3). Cryo-TEM images for $1 \mathrm{wt} \% \mathrm{~A}_{6} \mathrm{D}$ reveal the presence of thin nanosheet structures (Figure 3a and SI Figure S2) coexisting with irregular continuous network-like structures. We previously reported the formation of peptide nanosheets (under similar concentration conditions) for the related peptide with cationic headgroup $\mathrm{A}_{6} \mathrm{R}^{12}$ Nanosheet-like structures were also observed for solutions of the 2:1 mixture although here with a more defined width; i.e., nanotape-like structures are observed (Figure $3 \mathrm{~b}$ and SI Figure S3). For the 1:1 $\mathrm{A}_{6} \mathrm{D}$ :diamine solutions there was evidence for a high density of plate-like structures (Figure $3 c$ and SI Figure 4) as well as a region of irregular mesh-like structure. To our knowledge, such platelets have not previously been reported for self-assembling peptides. In contrast, no selfassembled structures were imaged for the 1:2 $\mathrm{A}_{6} \mathrm{D}$ :diamine mixtures, consistent with the lack of a CAC and the absence of observed secondary structure characteristics in the $C D$ spectrum.

Small-angle X-ray scattering (SAXS) was used to further probe the nature of the self-assembled nanostructures in solution. The corresponding measured intensity profiles with 


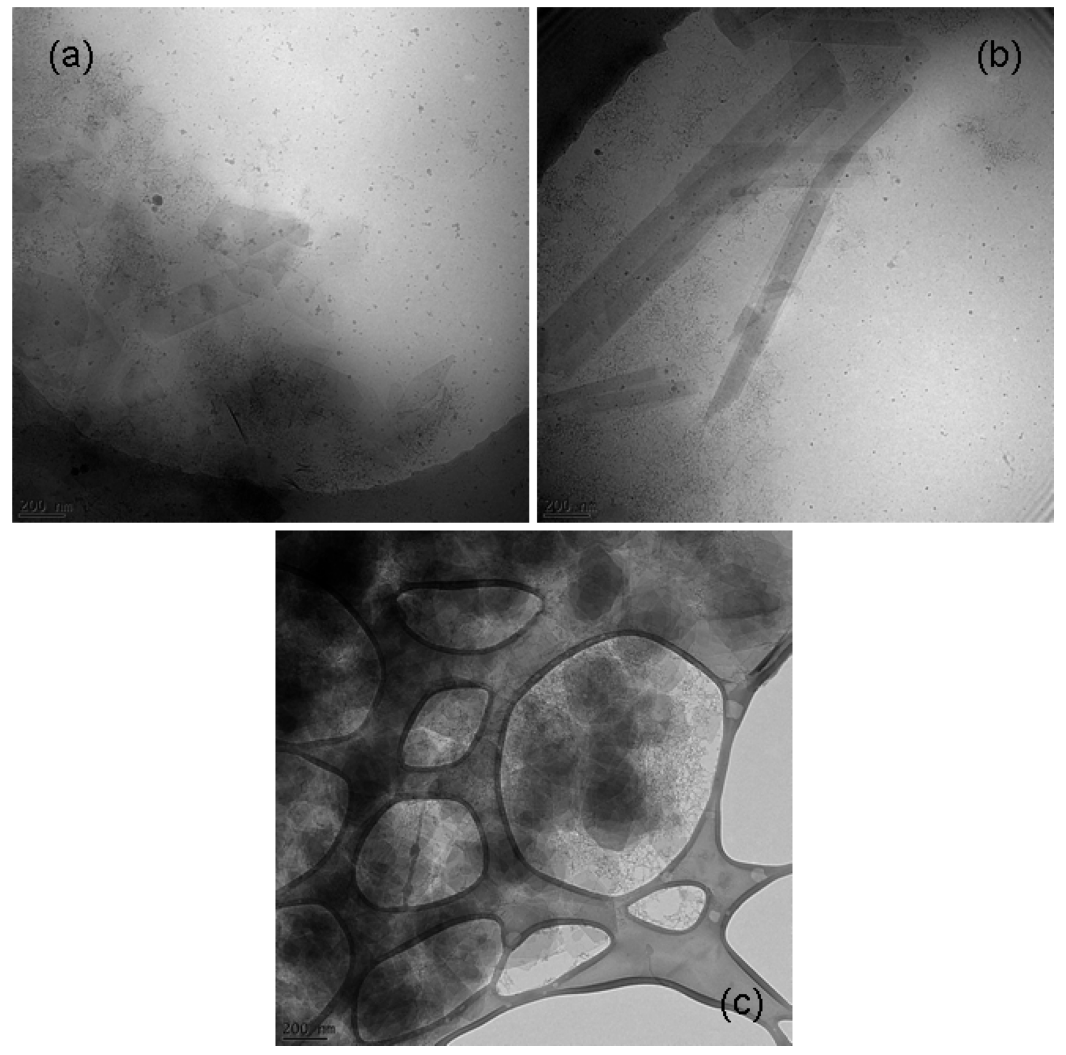

Figure 3. Cryo-TEM images: (a) 1 wt $\% \mathrm{~A}_{6} \mathrm{D}$; (b) 2:1 $\mathrm{A}_{6} \mathrm{D}$ :diamine; (c) 1:1 $\mathrm{A}_{6} \mathrm{D}$ :diamine. (Constant $\mathrm{A}_{6} \mathrm{D}$ concentration, 1 wt \%; ratios of $\mathrm{A}_{6} \mathrm{D}$ :diamine are molar ratios.)

model form factor fits are shown in Figure 4. The fit parameters are listed in Table 1 . The profile for 1 wt $\% \mathrm{~A}_{6} \mathrm{D}$ is very similar

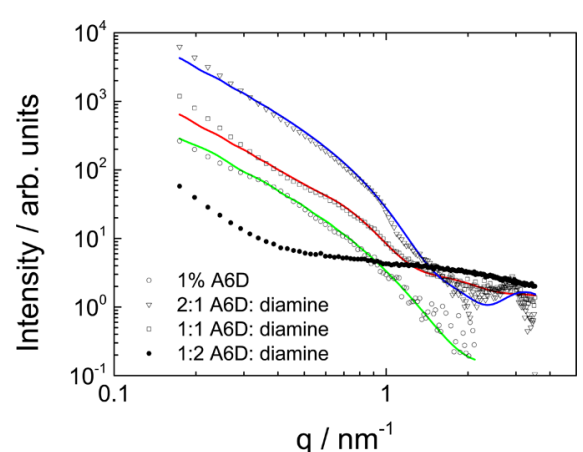

Figure 4. SAXS data (open symbols) with model form factor fits (solid lines). The fit parameters are listed in SI Table 2. For clarity, only every fifth measured data point is shown.

to that previously reported for 1 wt $\% \mathrm{~A}_{6} \mathrm{R}^{12}$ The data can be fitted to a "Gaussian bilayer" form factor, ${ }^{46}$ as described elsewhere; ${ }^{47-49}$ this form factor describes the electron density profile of a planar bilayer structure with three Gaussian functions representing the electron density of the core (here, hydrophobic A residues) and two for the surfaces (here, hydrophilic $D$ residues). Here, similar to the case of $A_{6} R$, ${ }^{12}$ we propose that $\mathrm{A}_{6} \mathrm{D}$ actually self-assembles into "monolayers" with a core of interdigitated $\mathrm{A}_{6}$ chains and surfaces of $\mathrm{D}$ residues (Figure 5). This is consistent with the fact that the layer thickness is determined to be $2.9 \mathrm{~nm}$, which is slightly larger than the estimated length of the chain in a parallel $\beta$ sheet $\left(7 \times 0.32 \mathrm{~nm}^{50}=2.2 \mathrm{~nm}\right)$ indicating interdigitation of the opposed chains (Figure 5) The low $q$ part of the SAXS data for the 2:1 $\mathrm{A}_{6} \mathrm{D}$ :diamine mixture can also be fitted using the Gaussian bilayer model, consistent with the cryo-TEM image which shows flat and wrapped layered structures (Figure $3 \mathrm{~b}$ ). At high $q$, a broad Bragg peak at $q_{0}=2.9 \mathrm{~nm}^{-1}$ is observed, corresponding to a structure with a periodicity $d=2.2 \mathrm{~nm}$. This is close to (but a little smaller than) the bilayer thickness obtained from the form factor fits, but identical to the estimated molecular length. Its presence suggests that some stacked layer structures (as well as isolated "monolayer" nanosheets) exist in the 2:1 mixture solution. The spacing of the stacked layer structures is smaller than that of the nanosheets, indicating complete interdigitation of the $\mathrm{A}_{6} \mathrm{D}$ peptide chains in this case). This Bragg peak was not accounted for in the form factor fitting. The SAXS data for the 1:1 mixture show a scaling lawtype decay of the intensity at low $q$ similar to that for the $\mathrm{A}_{6} \mathrm{D}$ and 2:1 mixtures (Figure 4). Because the cryo-TEM image for the 1:1 mixture shows flat platelets coexisting with irregular mesh structures (Figure 3c), the Gaussian bilayer form factor was supplemented with a contribution to allow for the mesh structure. For this purpose, we used the "broad peak" function (described in the footnotes in Table 1) to account for the presence of a broad peak in the measured SAXS data centered around $q_{0}=0.64 \mathrm{~nm}^{-1}$ (Figure 4). The SAXS profile for the 1:2 $\mathrm{A}_{6} \mathrm{D}$ :diamine solution showed a shape completely different from those for the other solutions, in particular a lack of any peak at higher $q$ due to a bilayer form factor (Figure 4), and was not fitted to a Gaussian bilayer form factor, consistent with the absence of aggregated structures in the cryo-TEM images. The SAXS profile for diamine alone (not shown) was not distinguishable from background (as expected for a dilute molecular solution). 
Table 1. SAXS Fitting Parameters (Fitted Using Gaussian Bilayer Form Factor ${ }^{46}$ )

\begin{tabular}{|c|c|c|c|c|c|c|}
\hline sample & $t^{a} / \mathrm{nm}$ & $\sigma_{\text {core }}, \sigma_{\text {out }}^{b} / \mathrm{nm}$ & $\nu_{\text {core }}{ }^{c}$ & $\nu_{\text {out }}^{d}$ & Gaussian polydispersity params $(t)^{e}$ & background $^{f}$ \\
\hline $\mathrm{A}_{6} \mathrm{D}$ & 2.9 & $0.5,0.5$ & 0.030 & 0.010 & $N=0.20, \sigma=0.7$ & 0.1 \\
\hline 2:1 $\mathrm{A}_{6} \mathrm{D}:$ diamine & 2.9 & $0.3,0.3$ & 0.027 & 0.025 & $N=0.8, \sigma=2.9$ & 0.1 \\
\hline 1:1 $\mathrm{A}_{6} \mathrm{D}:$ diamine $^{g}$ & 2.9 & $0.3,0.3$ & 0.0062 & 0.012 & $N=0.8, \sigma=0.7$ & 1.2 \\
\hline
\end{tabular}

${ }^{a}$ Bilayer thickness. ${ }^{b}$ Width for core (lipid chain) electron density, $\sigma_{\text {core }}$ and outer (peptide) electron density, $\sigma_{\text {out }}$ Gaussian functions (fixed). ${ }^{c}$ Scattering contrast of hydrophobic core of bilayer (with respect to solvent) (arbitrary units). ${ }^{d}$ Scattering contrast of hydrophilic surface of bilayer (with respect to solvent) (arbitrary units). ${ }^{e}$ Gaussian peak height $N$ and half-width $\sigma .{ }^{f}$ As well as the constant fixed background, the radius of the bilayer objects was fixed at $50 \mathrm{~nm}$. Since this is much larger than $t$, it does not influence the shape of the scattering profile. ${ }^{g}$ An additional "broad peak" function ${ }^{46}$ was included in the fit due to the observed mesh structure in the cryo-TEM images and the broad peak in the SAXS profile:

$$
I(q)=\frac{I_{0}}{\left(1+\left(\left|q-q_{0}\right| \xi\right)^{m}\right)^{p}}
$$

The parameters fitted were $I_{0}=13.1, \xi=2.7, q_{0}=0.64, m=1.82$, and $p=1.65$.

(a) $A_{6} D$

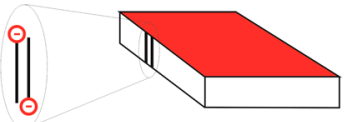

(b) $A_{6} D$ : diamine $2: 1$

(c) $A_{6} D$ : diamine 1:1

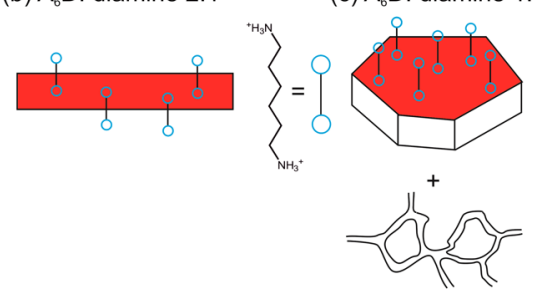

(d) $\mathrm{A}_{6} \mathrm{D}$ : diamine 1:2

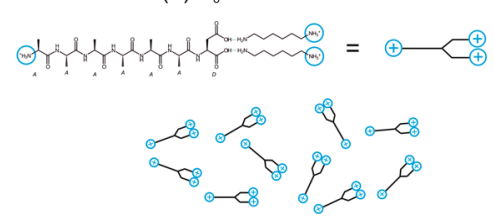

Figure 5. Schematic of self-assembly process: $A_{6} D$ versus $A_{6} D$ with hexamethylene diamine. (a) $\mathrm{A}_{6} \mathrm{D}$ forms nanosheets $2.2 \mathrm{~nm}$ thick comprising interdigitated molecules. (b) In the 2:1 mixture, binding of some diamine molecules drives the formation of nanotape structures. (c) For the 1:1 mixture, a higher degree of binding leads to platelets coexisting with a disordered mesh structure. (d) For the 1:2 mixture, $\mathrm{H}$-bonding interactions between the peptide $\mathrm{C}$ terminus and the $-\mathrm{NH}_{2}$ groups at one end of the diamine molecules lead to complexes with charged end groups as shown in solution, and these are not able to undergo self-assembly due to electrostatic interactions.

The information on nanostructure provided by cryo-TEM and SAXS (supported by the data on peptide conformation obtained from CD, FTIR, and XRD data) leads to the proposed schematic model shown in Figure 5. $\mathrm{A}_{6} \mathrm{D}$ forms nanosheets 2.9 $\mathrm{nm}$ thick comprising interdigitated molecules. In the 2:1 mixture, binding of some diamine molecules (to the carboxyl groups on the $\mathrm{D}$ residue and $\mathrm{C}$ terminus) drives the formation of nanotape structures. For the 1:1 mixture, a higher degree of binding leads to platelets coexisting with a disordered mesh structure. At the molecular level, the peptide loses its $\beta$-sheet conformation. For the 1:2 mixture, FTIR shows the presence of H-bonding interactions which stabilize complexes of one $\mathrm{A}_{6} \mathrm{D}$ molecule with two diamine molecules (Figure 5), leading to highly charged species which due to electrostatic repulsion of the free diamine $-\mathrm{NH}_{2}$ groups are stabilized in solution and do not undergo self-assembly. Data from measurements of $\mathrm{pH}$ titrating the hexamethylenediamine into $\mathrm{A}_{6} \mathrm{D}$ are shown in SI Figure $\mathrm{S} 5$ and show that in the range up to around $\mathrm{pH} 10$ the carboxyl and diamine amine groups are expected to be ionized since the $\mathrm{p} K_{\mathrm{a}}$ values of hexamethylenediamine are $\mathrm{p} K_{\mathrm{a}, 1}=11.02$ and $\mathrm{p} K_{\mathrm{a}, 2}=10.24 ;^{51,52}$ however, for the $2: 1$ mixture the diamine may not be fully charged; indeed the FTIR spectra suggest the presence of $\mathrm{H}$-bonding interactions between uncharged $\mathrm{NH}_{2}$ groups and $\mathrm{COOH}$ groups on the peptide. Note that the peptide $\mathrm{N}$ terminus is not necessarily expected to be fully charged for higher diamine content mixtures as its $\mathrm{pK}$ is typically considered to be approximately $8,{ }^{50,53}$ although values up to $\mathrm{p} K_{\mathrm{a}} 9.1$ have been reported. ${ }^{54} \zeta$ potential measurements (SI Table S1) indicate the presence of negatively charged species in all $\mathrm{A}_{6} \mathrm{D}$ :diamine mixtures and also show that the $\zeta$ potential in the $1: 2 \mathrm{~A}_{6} \mathrm{D}$ :diamine mixture is higher than in $1: 1$ or 2:1 mixtures suggesting that the peptide $\mathrm{N}$ terminus remains charged.

\section{CONCLUSIONS}

In summary, $\mathrm{A}_{6} \mathrm{D}$ self-assembles into ultrathin ( $3 \mathrm{~nm}$ thick) nanosheets above a critical aggregation concentration. The nanosheets are bilayers comprising interdigitated antiparallel $\mathrm{A}_{6} \mathrm{D}$ molecules in a $\beta$-sheet arrangement, leading to the covering of the nanosheet surfaces with aspartic acid residues. The presentation of such acidic residues at high density on a planar surface may be useful in future applications. It is presumed that the high charge density at the surfaces stabilizes a colloidal suspension of freely floating nanosheets.

Addition of a diamine is shown to be a valuable tool to modulate the self-assembly behavior and is a route to prepare acid-coated nanotapes and platelets upon addition of an appropriate amount of diamine. Addition of further diamine leads to the loss of $\beta$-sheet secondary structure and the formation of platelets coexisting with a bicontinuous structure. Upon addition of further amounts (two molar equivalents) of diamine, the self-assembled structure (and secondary structure) are lost completely and charged $\mathrm{A}_{6} \mathrm{D}$-diamine complexes are stable as isolated species in solution. The tight packing of the alanine residues (as evidenced by the very small $\beta$-sheet stacking distance revealed by the XRD studies discussed above) in $\mathrm{A}_{6} \mathrm{D}$ (and $\mathrm{A}_{6} \mathrm{R}$ studied previously ${ }^{12}$ ) is believed to favor the formation of densely packed nanosheets. The $A_{6} D$ nanosheets have multiple possible uses as biocompatible materials or substrates due to their functional bioactive and/or highly acidic 
nature. Acid-functionalized nanotubes, nanosheets, and platelets also have great potential as templates to create new nanomaterials.

\section{ASSOCIATED CONTENT}

\section{S Supporting Information}

The Supporting Information is available free of charge on the ACS Publications website at DOI: 10.1021/acs.langmuir.6b02180.

$\zeta$ potential measurement results, FTIR spectra, additional cryo-TEM images, and $\mathrm{pH}$ titration results (PDF)

\section{AUTHOR INFORMATION}

\section{Notes}

The authors declare no competing financial interest.

\section{ACKNOWLEDGMENTS}

This work was supported by EPSRC Grant EP/L020599/1 and STFC Grant ST/L502480/1 to I.W.H. The studentship of J.H. was supported by Medimmune and the University of Reading. We thank Ashkan Dehsorkhi for preliminary measurements on $\mathrm{A}_{6} \mathrm{D}$ and Sam Burholt for assistance with SAXS. We thank the ESRF for the award of bioSAXS beamtime on BM29 (ref MX1769) and Gabriele Giachin for assistance with the measurements. We are grateful to Nick Spencer (University of Reading) for the XRD measurements.

\section{REFERENCES}

(1) Tang, L.; Wang, Y.; Liu, Y.; Li, J. DNA-Directed Self-Assembly of Graphene Oxide with Applications to Ultrasensitive Oligonucleotide Assay. ACS Nano 2011, 5, 3817-3822.

(2) Wang, T. Q.; Wang, X. L.; Lu, Y.; Xiong, Q. Q.; Zhao, X. Y.; Cai, J. B.; Huang, S.; Gu, C. D.; Tu, J. P. Self-Assembly of Hierarchical $\mathrm{Fe}_{3} \mathrm{O}_{4}$ Microsphere/Graphene Nanosheet Composite: Towards a Promising High-Performance Anode for Li-Ion Batteries. RSC Adv. 2014, 4, 322-330.

(3) Yan, C. L.; Xue, D. F. Novel Self-Assembled MgO Nanosheet and Its Precursors. J. Phys. Chem. B 2005, 109, 12358-12361.

(4) Sun, Z. Q.; Liao, T.; Dou, Y. H.; Hwang, S. M.; Park, M.-S.; Jiang, L.; Kim, J. H.; Dou, S. X. Generalized Self-Assembly of Scalable TwoDimensional Transition Metal Oxide Nanosheets. Nat. Commun. 2014, 5, 3813.

(5) Fukuda, K.; Akatsuka, K.; Ebina, Y.; Ma, R.; Takada, K.; Nakai, I.; Sasaki, T. Exfoliated Nanosheet Crystallite of Cesium Tungstate with 2d Pyrochlore Structure: Synthesis, Characterization, and Photochromic Properties. ACS Nano 2008, 2, 1689-1695.

(6) Piorkowska, E., Rutledge, G. C., Eds. Handbook of Polymer Crystallization. Wiley-Blackwell: Chichester, U.K., 2013; DOI: 10.1002/9781118541838.

(7) Hamley, I. W. Crystallization in Block Copolymers. Adv. Polym. Sci. 1999, 148, 113-137.

(8) Nam, K. T.; Shelby, S. A.; Choi, P. H.; Marciel, A. B.; Chen, R.; Tan, L.; Chu, T. K.; Mesch, R. A.; Lee, B. C.; Connolly, M. D.; Kisielowski, C.; Zuckermann, R. N. Free-Floating Ultrathin TwoDimensional Crystals from Sequence-Specific Peptoid Polymers. Nat. Mater. 2010, 9, 454-460.

(9) Kudirka, R.; Tran, H.; Sanii, B.; Nam, K. T.; Choi, P. H.; Venkateswaran, N.; Chen, R.; Whitelam, S.; Zuckermann, R. N. Folding of a Single-Chain, Information-Rich Polypeptoid Sequence into a Highly Ordered Nanosheet. Biopolymers 2011, 96, 586-595.

(10) Mannige, R. V.; Haxton, T. K.; Proulx, C.; Robertson, E. J.; Battigelli, A.; Butterfoss, G. L.; Zuckermann, R. N.; Whitelam, S. Peptoid Nanosheets Exhibit a New Secondary-Structure Motif. Nature 2015, 526, 415-420.
(11) Zhang, S. G.; Holmes, T.; Lockshin, C.; Rich, A. Spontaneous Assembly of a Self-Complementary Oligopeptide to Form a Stable Macroscopic Membrane. Proc. Natl. Acad. Sci. U. S. A. 1993, 90, 33343338.

(12) Hamley, I. W.; Dehsorkhi, A.; Castelletto, V. Self-Assembled Arginine-Coated Peptide Nanosheets in Water. Chem. Commun. 2013, $49,1850-1852$.

(13) Jiang, T.; Xu, C. F.; Zuo, X. B.; Conticello, V. P. Structurally Homogeneous Nanosheets from Self-Assembly of a Collagen-Mimetic Peptide. Angew. Chem., Int. Ed. 2014, 53, 8367-8371.

(14) Hara, E.; Ueda, M.; Kim, C. J.; Makino, A.; Hara, I.; Ozeki, E.; Kimura, S. Suppressive Immune Response of Poly-(Sarcosine) Chains in Peptide-Nanosheets in Contrast to Polymeric Micelles. J. Pept. Sci. 2014, 20, 570-577.

(15) Dai, B.; Li, D.; Xi, W.; Luo, F.; Zhang, X.; Zou, M.; Cao, M.; Hu, J.; Wang, W. Y.; Wei, G. H.; Zhang, Y.; Liu, C. Tunable Assembly of Amyloid-Forming Peptides into Nanosheets as a Retrovirus Carrier. Proc. Natl. Acad. Sci. U. S. A. 2015, 112, 2996-3001.

(16) da Silva, E. R.; Walter, M. N. M.; Reza, M.; Castelletto, V.; Ruokolainen, J.; Connon, C. J.; Alves, W. A.; Hamley, I. W. SelfAssembled Arginine-Capped Peptide Bolaamphiphile Nanosheets for Cell Culture and Controlled Wettability Surfaces. Biomacromolecules 2015, 16, 3180-3190.

(17) Hamley, I. W. Self-Assembly of Amphiphilic Peptides. Soft Matter 2011, 7, 4122.

(18) Zhao, X.; Pan, F.; Xu, H.; Yaseen, M.; Shan, H.; Hauser, C. A.; Zhang, S.; Lu, J. R. Molecular Self-Assembly and Applications of Designer Peptide Amphiphiles. Chem. Soc. Rev. 2010, 39, 3480-98.

(19) Dehsorkhi, A.; Castelletto, V.; Hamley, I. W. Self-Assembling Amphiphilic Peptides. J. Pept. Sci. 2014, 20, 453-467.

(20) Santoso, S. S.; Vauthey, S.; Zhang, S. Structures, Function and Applications of Amphiphilic Peptides. Curr. Opin. Colloid Interface Sci. 2002, 7, 262-266.

(21) Vauthey, S.; Santoso, S.; Gong, H.; Watson, N.; Zhang, S. Molecular Self-Assembly of Surfactant-Like Peptides to Form Nanotubes and Nanovesicles. Proc. Natl. Acad. Sci. U. S. A. 2002, 99, 5355-5360.

(22) von Maltzahn, G.; Vauthey, S.; Santoso, S.; Zhang, S. Positively Charged Surfactant-Like Peptides Self-Assemble into Nanostructures. Langmuir 2003, 19, 4332-4337.

(23) Hauser, C. A. E.; Zhang, S. G. Designer Self-Assembling Peptide Nanofiber Biological Materials. Chem. Soc. Rev. 2010, 39, 2780-2790.

(24) Nagai, A.; Nagai, Y.; Qu, H. J.; Zhang, S. G. Dynamic Behaviors of Lipid-Like Self-Assembling Peptide $\mathrm{A}_{6} \mathrm{D}$ and $\mathrm{A}_{6} \mathrm{~K}$ Nanotubes. J. Nanosci. Nanotechnol. 2007, 7, 2246-2252.

(25) Khoe, U.; Yang, Y. L.; Zhang, S. G. Synergistic Effect and Hierarchical Nanostructure Formation in Mixing Two Designer LipidLike Peptide Surfactants Ac- $\mathrm{A}_{6} \mathrm{D}-\mathrm{OH}$ and Ac- $\mathrm{A}_{6} \mathrm{~K}-\mathrm{NH}_{2}$. Macromol. Biosci. 2008, 8, 1060-1067.

(26) Zhuang, F.; Oglecka, K.; Hauser, C. A. E. Self-Assembled Peptide Surfactants $\mathrm{A}_{6} \mathrm{~K}$ and $\mathrm{A}_{6} \mathrm{D}$ Adopt $\alpha$-Helical Structures Useful for Membrane Protein Stabilization. Membranes 2011, 1, 314-326. Oglecka, K.; Zhuang, F.; Hauser, C. A. E. Correction: Self-Assembled Peptide Surfactants $\mathrm{A}_{6} \mathrm{~K}$ and $\mathrm{A}_{6} \mathrm{D}$ Adopt $\alpha$-Helical Structures Useful for Membrane Protein Stabilization. Membranes 2012, 2, 214-215.

(27) Wang, X. Q.; Corin, K.; Baaske, P.; Wienken, C. J.; JerabekWillemsen, M.; Duhr, S.; Braun, D.; Zhang, S. G. Peptide Surfactants for Cell-Free Production of Functional G Protein-Coupled Receptors. Proc. Natl. Acad. Sci. U. S. A. 2011, 108, 9049-9054.

(28) Fatouros, D. G.; Lamprou, D. A.; Urquhart, A. J.; Yannopoulos, S. N.; Vizirianakis, I. S.; Zhang, S. G.; Koutsopoulos, S. Lipid-Like SelfAssembling Peptide Nanovesicles for Drug Delivery. ACS Appl. Mater. Interfaces 2014, 6, 8184-8189.

(29) Dou, Y.; Xu, H.; Hao, J. Self-Assembly and Accurate Preparation of Au Nanoparticles in the Aqueous Solution of a Peptide $\mathrm{A}_{6} \mathrm{D}$ and a Zwitterionic $\mathrm{C}_{14}$ dmao. Soft Matter 2013, 9, 5572-5580.

(30) Yaghmur, A.; Laggner, P.; Zhang, S. G.; Rappolt, M. Tuning Curvature and Stability of Monoolein Bilayers by Designer Lipid-Like Peptide Surfactants. PLoS One 2007, 2, e479. 
(31) Penfold, J.; Thomas, R. K.; Li, P. X. Biogenic Amine - Surfactant Interactions at the Air-Water Interface. J. Colloid Interface Sci. 2015, 449, 167-174.

(32) Penfold, J.; Thomas, R. K.; Li, P. X. Impact of Biogenic Amine Molecular Weight and Structure on Surfactant Adsorption at the AirWater Interface. J. Colloid Interface Sci. 2016, 463, 199-206.

(33) Castelletto, V.; Gouveia, R. J.; Connon, C. J.; Hamley, I. W.; Seitsonen, J.; Nykänen, A.; Ruokolainen, J. Alanine-Rich Amphiphilic Peptide Containing the RGD Cell Adhesion Motif: A Coating Material for Human Fibroblast Attachment and Culture. Biomater. Sci. 2014, 2, $362-369$.

(34) Bulheller, B. M.; Rodger, A.; Hirst, J. D. Circular and Linear Dichroism of Proteins. Phys. Chem. Chem. Phys. 2007, 9, 2020-2035.

(35) Nordén, B.; Rodger, A.; Dafforn, T. R. Linear Dichroism and Circular Dichroism: A Textbook on Polarized-Light Spectroscopy; Royal Society of Chemistry: Cambridge, U.K., 2010.

(36) Kelly, S. M.; Jess, T. J.; Price, N. C. How to Study Proteins by Circular Dichroism. Biochim. Biophys. Acta, Proteins Proteomics 2005, 1751, 119-139.

(37) Stuart, B. Biological Applications of Infrared Spectroscopy; Wiley: Chichester, U.K., 1997.

(38) Barth, A. Infrared Spectroscopy of Proteins. Biochim. Biophys. Acta, Bioenerg. 2007, 1767, 1073-1101.

(39) Barth, A.; Zscherp, C. What Vibrations Tell Us About Proteins. Q. Rev. Biophys. 2002, 35, 369-430.

(40) Bellamy, L. J. The Infrared Spectra of Complex Molecules; Chapman and Hall: London, 1975.

(41) Haris, P.; Chapman, D. The Conformational Analysis of Peptide Using Fourier Transform IR Spectroscopy. Biopolymers 1995, 37, 251-263.

(42) Arnott, S.; Dover, S. D.; Elliott, A. Structure of Beta-Poly-LAlanine: Refined Atomic Co-Ordinates for an Anti-Parallel BetaPleated Sheet. J. Mol. Biol. 1967, 30, 201-8.

(43) Fujie, A.; Komoto, T.; Oya, M.; Kawai, T. Crystallization of Polypeptides in Course of Polymerization, III. Further Studies on Growth Mechanisms of Poly(L-Alanine) Crystals. Makromol. Chem. 1973, 169, 301-321.

(44) Rathore, O.; Sogah, D. Y. Self-Assembly of $\beta$-Sheets into Nanostructures by Poly(Alanine) Segments Incorporated in Multiblock Copolymers Inspired by Spider Silk. J. Am. Chem. Soc. 2001, 123, 5231-5239.

(45) Hamley, I. W.; Dehsorkhi, A.; Castelletto, V.; Seitsonen, J.; Ruokolainen, J.; Iatrou, H. Self-Assembly of a Model Amphiphilic Oligopeptide Incorporating an Arginine Headgroup. Soft Matter 2013, 9, 4794-4801.

(46) Bressler, I.; Kohlbrecher, J.; Thünemann, A. F. Sasfit: A Tool for Small-Angle Scattering Data Analysis Using a Library of Analytical Expressions. J. Appl. Crystallogr. 2015, 48, 1587-1598.

(47) Pabst, G.; Rappolt, M.; Amenitsch, H.; Laggner, P. Structural Information from Multilamellar Liposomes at Full Hydration: Full QRange Fitting with High Quality X-Ray Data. Phys. Rev. E: Stat. Phys., Plasmas, Fluids, Relat. Interdiscip. Top. 2000, 62, 4000-4009.

(48) Castelletto, V.; Cheng, G.; Stain, C.; Connon, C. J.; Hamley, I. W. Self-Assembly of a Peptide Amphiphile Containing L-Carnosine and Its Mixtures with a Multilamellar Vesicle Forming Lipid. Langmuir 2012, 28, 11599-11608.

(49) Castelletto, V.; Gouveia, R. J.; Connon, C. J.; Hamley, I. W. New RGD- Peptide Amphiphile Mixtures Containing a Negatively Charged Diluent. Faraday Discuss. 2013, 166, 381-397.

(50) Creighton, T. E. Proteins. Structures and Molecular Properties; W. H. Freeman: New York, 1993.

(51) Barbucci, R.; Paoletti, P.; Vacca, A. Predictions of the Enthalpies of Protonation of Amines. Log $\mathrm{K}, \Delta \mathrm{H}$ and $\Delta \mathrm{S}$ Values for the Protonation of Ethylenediamine and Tri-, Tetra-, Penta- and HexaMethylenediamine. J. Chem. Soc. A 1970, 0, 2202-2206.

(52) Perrin, D. D. Dissociation Constants of Organic Bases in Aqueous Solution; Butterworth: London, 1972.

(53) Berg, J. M.; Tymoczko, J. L.; Stryer, L. Biochemistry, 6th ed.; W. H. Freeman: New York, 2007.
(54) Grimsley, G. R.; Scholtz, J. M.; Pace, C. N. A Summary of the Measured pK Values of the Ionizable Groups in Folded Proteins. Protein Sci. 2009, 18, 247-251. 